0.52 per cent and 0.46 per cent.) An explanation for the disproportionate excretion of calcium-45 and total calcium under these conditions may possibly be found in a different partitioning of the injected label among the body calcium pools.

Robert C. LIKINS

Dorts L. Craven

Laboratory of Biochemistry,

National Institute of Dental Research,

National Institutes of Health, Bethesda, Maryland.

${ }^{1}$ Likins, R. C., Posner, A. S., Kunde, M. L., and Craven, D. L., Arch. Biochem. Biophys., 83, 472 (1959).

\section{Uptake of Phosphorus-32 by the Roots of Lolium perenne}

Previous work on the ability of various portions of the root to supply the shoot with minerals has been carried out using the seminal roots of cereals grown in nutrient solution when the plants were a few days old. Weibe and $\mathrm{Kramer}^{1}$ considered that in barley the most active zone of absorption and translocation of minerals was situated some distance behind the tip. The results of Lundegårdh ${ }^{2}$, also working on barley, indicated that most nitrate was translocated from the basal portion of the root, that is, that nearest the shoot.

Young seminal roots grown in nutrient solution may not be directly comparable with older nodal roots. The present experiments were conducted with plants of Lolium perenne a few weeks old which had been grown in soil and possessed several nodal roots. Just before the experimental treatments the roots were washed free from soil. All plants the roots of which showed signs of decay were rejected.

The absorption and translocation of phosphorus were studied using phosphorus-32. This was received carrier-free in dilute hydrochloric acid, which was added as required to the Hoagland solution. The plants were allowed to absorb the phosphorus-32 from this solution for $6 \mathrm{hr}$. The amount in the shoot tissue after this period was estimated by drying the material, digesting it with concentrated sulphuric acid and then measuring the activity of the resulting liquid, after making it up to a known volume.

In the first series of experiments, the ability of one portion of a root to absorb and translocate phosphorus32 was studied. A portion of $12 \mathrm{~mm}$. of one root of each plant was isolated by passing the root through a cellulose test-tube which had two holes opposite each other in its side. The junctions between the root and the test-tube were made watertight with simple ointment. Radioactive Hoagland solution $(2 \mathrm{ml}$. with an activity of $5 \mu \mathrm{c}$.) was put in the test-tube while the rest of the root system was bathed in normal Hoagland solution.

The results of one experiment with white unbranched nodal roots $10-12 \mathrm{~cm}$. long are presented in Table 1. The basal region absorbed most phos.

Table 1. Uptake of Phosphords-32 and its Translocation to the

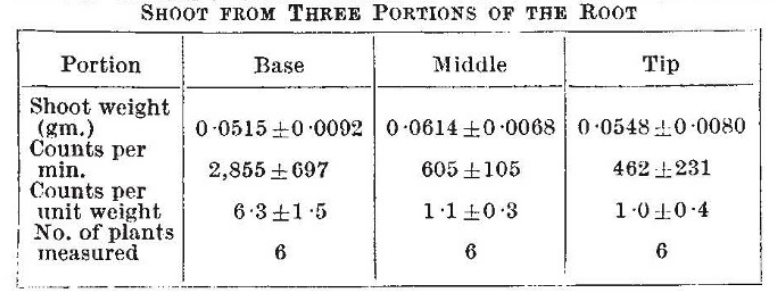

Table 2. EFFECT OF CUTTING OFF THE ROOTS AT 2 CM. FROM THE BASE OF THE SHOOT ON THE UPTAKE OF PHOSPhORUS-32 AND ITS \begin{tabular}{|l|c|c|c|}
\multicolumn{4}{c}{ TRANSLOCATION TO THE SHOOT } \\
\hline & Uncut & Cut & S.E. \\
\hline Shoot weight (gm.) & 0.0705 & 0.0728 & 0.0041 \\
Counts per ninin. & 1,447 & 1,055 & 140 \\
Counts per unit weight & 2.03 & 1.46 & 0.19 \\
Total root weight (gm.) & 0.0362 & 0.0337 & 0.0037 \\
Weight of root cut off (gm.) & -12 & 0.0259 & $=$ \\
No. of plants measured & 12 & 12 & - \\
\hline
\end{tabular}

phorus-32 which was translocated to the shoot. Similar results were obtained in other experiments.

The value of the basal portion of the root was confirmed by an experiment in which plants with intact root systems were compared with plants the roots of which had been cut off $2 \mathrm{~cm}$. from the base of the shoot. The roots of both series of plants were immersed in Hoagland solution to which phosphorus32 had been added to give it an activity of 100 ic. per litre. Although the 'cut' plants had 77 per cent of their roots removed, the amount of phosphorus-32 reaching the shoots was only reduced by 28 per cent.

These experiments strongly suggest that it is from the basal portions of the roots that the shoot receives most of its phosphorus. The top few inches of the soil would therefore appear to be most important for the mineral nutrition of the plant. Boggie et al. ${ }^{3}$ found that grasses absorbed more phosphorus-32 from the upper $10 \mathrm{~cm}$. of the soil than from greater depths.

According to Stout and Hoagland the phosphorus32 would have to reach the xylem before it could be distributed throughout the plant. It would seem, therefore, that the thickened endodermis found in this region of the root ${ }^{5}$ was not an effective barrier to the inward movement of ions, as suggested by Weibe and $\mathrm{Kramer}^{1}$. Alternatively, there may have been considerable downward movement of phosphorus-32 in the cortex either to the younger regions of the root where the endodermis was not thickened, as suggested by Soper ${ }^{5}$, or upwards to the junction of the root and shoot. If the thickened endodermis was an effective barrier, the plants with 'cut' roots in the second experiment must have absorbed the phosphorus-32 through the exposed xylem on the cut surface.

This work was carried out during the tenure of a New Zealand National Research Fellowship at the Department of Scientific and Industrial Research, Plant Physiology Unit, Grasslands Division, Palmerston North, New Zealand. Acknowlodgment is due to Dr. K. J. Mitchell for help and advice. ARTHUR Troughton

Welsh Plant Breeding Station, Plas Gogerddan, Aberystwyth.

'Weibe, H. H., and Kramer, P. J., Plant Physiol., 29, 342 (1954). ${ }^{2}$ Lundegärdh, H., Physiol. Plant., 3, 103 (1950).

${ }^{3}$ Boggie, R., Hunter, R. F., and Knight, A. H., J. Ecol., 621 (1958).

4 Stout, P. R., and Hoagland, D. R., Amer. J. Bot., 28, 320 (1940). "Soper, K., N.Z. J. Agric. Res., 2, 329 (1959).

\section{BIOPHYSICS}

\section{Physico-chemical Properties of Purified Cytochrome a}

THE enzymatic and spectral properties of purified cytochrome $a$ isolated from animal tissues in soluble form have been studied by many investigators. However, a number of questions remain unanswered as to its physico-chemical properties. In previous 